\section{Do you really know how tall}

\section{you are?}

Whereas it is customary for patients seen in ambulatory care settings to have their weights measured, heights are usually taken from the patient's recollection. To see if this practice may result in incorrect estimates of body mass index for people with diabetes, Ioo consecutive adult outpatients newly referred for consultation regarding diabetes ( 32 patients with type I diabetes and 68 patients with type 2 diabetes; 47 women and 53 men) were asked what they believed their height to be, then had their height and weight measured.

Only I8 of the roo patients correctly estimated their height within 0.5 inch of its measured value. Of the remaining 82 patients, 76 overestimated their height by more than 0.5 inch (including 14 who overestimated their height by 2 inches, 5 by 2.5 inches, 4 by 3 inches and I by 4 inches). Only 6 patients underestimated their height by more than 0.5 inch.

When measured rather than recollected heights were used, 4 patients moved from the normal range of the body mass index $\left(18.5-24.9 \mathrm{~kg} / \mathrm{m}^{2}\right)$ into the overweight range (25.0-29.9 $\mathrm{kg} / \mathrm{m}^{2}$ ), II patients moved from the overweight range into the obese class I range $\left(30.0-34.9 \mathrm{~kg} / \mathrm{m}^{2}\right)$ and 6 patients moved from the obese class I range into the obese class II range ( $>35.0$ $\mathrm{kg} / \mathrm{m}^{2}$ ). In contrast, 2 patients were reclassified as being in the normal range rather than the overweight range and I patient was reclassified as being in the obese class I range rather than the obese class II range.

The patient's type of diabetes was not a predictor of their ability to accurately estimate their height, nor was their age. (The mean age of patients estimating their height within I inch of its measured value was 48 years; the mean age of those estimating their height to be more than I inch greater or less than its measured value was 50 years). Women, however, were more likely to accurately estimate their height ( 35 of 47 women v. 24 of 53 men estimated their height within $\mathrm{I}$ inch of its measured value, $p=0.003$ ).
Aspirations for greater stature in life are clearly more than just figurative.

\section{Ian Blumer}

Internist

Ajax, Ont.

Author's note: Subsequent to the completion of this study I measured my own height. This was 5 feet, 8.5 inches, which is exactly I inch shorter than I had thought.

DOI:I0.1503/cmaj.106or6o

\section{Safe prescribing}

Kaveh Shojania proposes several solutions to the pitfalls associated with illegible or hard-to-interpret prescriptions, including 2 suggestions of ways to prevent misinterpretation of written prescriptions. ${ }^{1}$ The first and best, according to the author, is to have physicians indicate both the generic and the brand names of a medication on the prescription, with the example "Zyrtec (cetirizine)" mentioned for illustration. Although this idea may appear logical and foolproof, it might lead to the dispensing of more expensive medications, since, on reading the prescription, the pharmacist may interpret it to mean that only the branded version of the product should be used.

The second proposed solution is to write the indication along with the product (as in "Zyrtec for rash"), but this approach, too, has drawbacks. What would the author have written if prescribing Zyprexa (olanzapine) for the dishevelled person described in case I? I also wonder if the legal and ethical aspects of this suggestion have been reasonably examined. These concerns arise from my experience as a former pharmacist and a practising psychiatrist. With this background, I recognize that although physicians may take for granted the confidentiality of data on their prescribing habits (as collected by IMS and sold to pharmaceutical companies), ${ }^{2,3}$ this may not be the case. At present, disclosing too much information without adequate safeguards has the potential to create problems not easily anticipated by prescribing physicians.

Finally, the author suggests that electronic prescribing will prevent medication errors. I agree that it may aid in this arena, although the safeguards against legal and ethical issues are far from clear. Wouldn't it be a shame to see e-prescribing evolve into mass marketing, whereby prescribers are bombarded by email messages from competing pharmaceutical companies for each product that they prescribe?

\section{Nadeem Bhanji \\ Assistant Clinical Professor \\ University of Calgary \\ Calgary, Alta.}

\section{REFERENCES}

I. Shojania KG. Safe medication prescribing and monitoring in the outpatient setting. CMAJ 2006; I74(9):I257-8.

2. Zoutman DE, Ford BD, Bassili AR. A call for the regulation of prescription data mining. $C M A J$ 2000;163(9):1146-8

3. Whitney J. Pharmaceutical sales Ior: inside information. Guernica [serial on Internet] $2006 \mathrm{Apr}$. Available: www.guernicamag.com/features/I59 /inside_information/ (accessed 2006 May 29).

DOI:I0.I503/cmaj.I060I05

\section{[Dr. Shojania responds:]}

Even the most plausible, well-intentioned interventions to improve care can be undermined in unexpected ways. ${ }^{1}$ Thus, I fully support subjecting proposed safety interventions to the type of critique offered by Nadeem Bhanji. Nonetheless, I think the recommendations I made remain reasonable.

Bhanji worries that pharmacists will interpret prescriptions that include both the generic and the brand names of a medication as requiring dispensation of the brand name drug. If "Do not substitute" is not written on the prescription, I think most pharmacists would proceed with whatever generic substitution they would usually make. In fact, many provinces mandate such substitutions. ${ }^{2,3}$

I agree that the alternative solution of stating the indication for the medication requires discretion. For potentially sensitive conditions I would suggest that physicians use the generic name plus brand name approach and ask their patients for permission to include specific diagnoses on their prescriptions. Another possibility is to use preprinted pre- 